\title{
DIVERSIDADE SEXUAL, GÊNERO E SEXUALIDADES: TEMAS IMPORTANTES À EDUCAÇÃO DEMOCRÁTICA ${ }^{1}$
}

\author{
Marcio Caetano ${ }^{1}$, Carlos Henrique Lucas Lima², Amanda Motta Castro ${ }^{3}$ \\ ${ }^{1}$ Pós-doutorando no Programa de Pós-Graduação em Educação da Universidade do Estado do Rio de Janeiro - UERJ. \\ Docente do Programa de Pós-Graduação em Educação na Universidade Federal do Rio Grande - FURG \\ ${ }^{2}$ Doutor em Cultura e Sociedade pela Universidade Federal da Bahia - UFBA. Docente e coordenador no Programa de \\ Pós-Graduação em Ciências Humanas e Sociais (PPGCHS/UFOB). \\ ${ }^{3}$ Docente do Programa de Pós-graduação em Educação da Universidade Federal do Rio Grande - FURG, docente do \\ Instituto de Educação e pesquisadora do Líder do Nós do Sul.
}

\section{RESUMO}

Este ensaio faz algumas observações acerca dos conceitos de gênero, sexualidade, orientação sexual e identidade de gênero, temas sobre os quais, mais do que nunca, se faz necessário refletir nos contextos escolares. As reflexões aqui realizadas foram formuladas no interior de projetos de pesquisa que têm como preocupação a construção das identidades de gênero na escola e compõe parte de experiências formativas com docentes dos estados da Bahia e do Rio Grande do Sul. O ensaio defende uma escola que, ao interrogar as diferenças, eduque para o respeito às dissidências de gênero e sexualidade, compreendendoas como parte indissociável da sociedade democrática e cidadã. Além disso, o texto se propõe a oferecer alguns apontamentos epistemológicos om vistas a enfrentar os discursos conservadores que no tempo presente voltam suas forças contra uma educação cidadã, cujo principal propósito reside na ampliação dos direitos humanos, na participação política e da noção de humanidade.

Palavras-chave: Educação democrática. Direitos humanos. Estudos queer.

\section{SEXUAL DIVERSITY, GENDER AND SEXUALITY: IMPORTANT THEMES TO DEMOCRATIC EDUCATION}

\section{ABSTRACT}

This essay has some observations on the concepts of gender, sexuality, sexual orientation and gender identity, themes that, but never, are necessary to reflect on the school contexts. The reflections that have been made here have been formulated within research projects that deal with the construction of gender identities in the school and part of the formative experiences with teachers of the states of Bahia and Rio Grande do Sul. The teaching defends a school that, in interrogating the differences, educating the recognition of gender and sexuality dissent, I understand them as inseparable parts of democratic and city society. In addition, the text proposes to offer some epistemological notes to confront the conservative discourses that in the present day renew their fights against the city education, whose main objective is the expansion of human rights, the political participation and the notion of humanity.

Keywords: Democratic education. Human rights. Queer studios.

\section{DIVERSIDAD SEXUAL, GÉNERO y SEXUALIDADES: TEMAS IMPORTANTES A IA EDUCACIÓN DEMOCRÁTICA}

\section{RESUMEN}

Este ensayo hace algunas observaciones sobre los conceptos de género, sexualidad, orientación sexual e identidad de género, temas que, más que nunca, son necesarios para reflexionar sobre los contextos escolares. Las reflexiones hechas aquí fueron formuladas dentro de proyectos de investigación que se ocupan de la construcción de identidades de género en la escuela y son parte de experiencias formativas con docentes de los estados de Bahia y Rio Grande do Sul. El ensayo defiende una escuela que, ao

\footnotetext{
${ }^{1}$ As análises que integram este artigo formam parte das pesquisas desenvolvidas por seus autores nos espaços institucionais em que atuam, a exemplo do estágio de pós-doutorado no ProPEd/UERJ, financiado pela Capes, do primeiro autor.
} 
interrogar las diferencias, eduque al reconocimiento de la disidencia de género y sexualidad, entendiéndolos como partes inseparables de la sociedad democrática y ciudadana. Además, el texto propone ofrecer algunas notas epistemológicas para confrontar los discursos conservadores que en la actualidad vuelven sus fuerzas contra la educación ciudadana, cuyo objetivo principal radica en la expansión de los derechos humanos, la participación política y la noción de humanidad.

Palabras-clave: Educación democrática. Derechos humanos. Estudios queer.

\section{INTRODUÇÃO}

Há já quase trinta anos ${ }^{2}$, o Brasil tem visto florescer em suas universidades grupos e núcleos de estudo dedicados a pesquisas relacionadas ao feminismo, teorias de gênero e sexualidades $^{3}$. Os primeiros grupos, em um primeiro momento, estavam preocupados centralmente com a desigualdade sexuais sustentadas pela sociedade patriarcal. Neste contexto, os primeiros movimentos acadêmicos passaram a se dedicar a descrever e a analisar os processos produtores dessas desigualdades e a propor estratégias nos campos da cultura e das políticas públicas visando à superação de assimetrias sexuais.

Os conceitos forjados nos Estudos de Gênero e/ou Feministas estavam inseridos em momentos de profundas alterações acadêmicas e, por vezes, nos debates político-econômicos. Ao considerar o sexo como um feito cultural, em vez de fator, por si, natural, os debates do campo correspondiam ao propósito de questionar as diferenças entre os sexos nas agendas acadêmicas e políticas. Os corpos sexuais foram retirados do domínio exclusivo do campo biológico e suas análises foram orientadas a partir das questões culturais da sociedade patriarcal. Não obstantes aos feitos, outras constatações feitas pelos Estudos feministas, de Gênero e de Sexualidades podem ser apontadas, mas para o que aqui cabe dizer, foram esses campos de estudos que viabilizaram a formulação de formas de superação das assimetrias de

\footnotetext{
2 Dois são os grupos e/ou núcleos de pesquisa sobre gênero e sexualidade cujas institucionalizações datam da década de 1990: o GEERGE, sediado na Universidade Federal do Rio Grande do Sul (UFRGS) e o Núcleo de Estudos de Gênero - PAGU, sediado na Universidade Estadual de Campinas (Unicamp).

${ }^{3}$ Mais recentemente, o país tem testemunhado o surgimento e consequente institucionalização de grupos de pesquisa organizados em torno de perspectivas queer/desconstrucionistas. Dentre esses grupos, destaca-se, hoje, no Brasil, o CuS - Cultura e Sexualidade, fundado em 2006 na Universidade Federal da Bahia (UFBA) e o Nós do Sul - Laboratório de Estudos e Pesquisas sobre Identidades, Currículos e Culturas, fundado em 2014, na Universidade Federal do Rio Grande (FURG).
}

gênero ou o que pesquisas mais recentes vêm chamando desconstrução das ideias de gênero e sexualidade (LOURO, 2001) ${ }^{4}$.

A desconstrução do gênero se propõe a interrogar/desnaturalizar os processos sociais, culturais, econômicos e políticos, e, portanto, historicamente localizados, que permitiram a produção de marcadores das diferenças sexuais. Desconstruir significa fazer os seguintes questionamentos: o entendimento que temos atualmente sobre mulheres e homens é algo natural ou foi formulado em determinado momento da história, obedecendo a contingenciamentos? $E$ mais: quem ganha $e$ quem perde com a vitória desse entendimento? Se à primeira pergunta dizemos que o entendimento que nossas sociedades possuem sobre o gênero é natural, ou seja, inerentes às pessoas, então não há possibilidade de ação, e as relações de gênero não terão outra escapatória que permanecerem tal como estão hoje. Se, ao contrário, dissermos à primeira pergunta: "há um momento historicamente localizável em que é possível apontar o surgimento da compreensão que possuímos sobre o que é o gênero e as sexualidades", então tal compreensão pode ser descrita e, consequentemente, desfeita por meio de estratégias sociais, políticas, econômicas e culturais $^{5}$ e no campo das leis visando a seu

\footnotetext{
${ }^{4}$ Fortemente inspirados em perspectivas desconstrucionistas de base derridiana, os Estudos Queer, que têm sua introdução e desenvolvimento no Brasil a partir da publicação do artigo "Teoria Queer - Uma Política Pós-Identitária para a Educação", de Guacira Lopes Louro (2001), não visam a uma destruição do gênero e da sexualidade, mas sim a sua desconstrução, quer dizer, seu propósito maior assenta em descobrir o gênero e a sexualidade do caráter de naturalidade adquirido ao longo da história. A genealogia (FOUCAULT, 1979) compõe o arsenal crítico desconstrutor/queer ao tornar visíveis as contingências históricas, os sistemas de interesse e as relações de poder presentes quando da emergência das categorias que ordenam o mundo, incluídas aí, as identidades de gênero e sexualidade. Em Que os outros sejam o normal (2015), Leandro Colling dá conta, entre outras questões, de apresentar os principais compromissos de ativismos e pesquisas de base queer e outros mais sintonizados com o que ele chama "mainstream", ou seja, mais institucionalizados.

Duas observações precisam ser feitas: uma diz respeito à compreensão que temos da educação como parte integrante da
} 
desmonte. Se algo é histórico e cultural, é, portanto, desconstruível.

Por exemplo, quem nos lê deve se lembrar que até a década de 1930 no Brasil as mulheres não possuíam plenos direitos políticos, como, por exemplo, o direito ao voto. Até essa década, as mulheres foram privadas de exercerem essa dimensão cidadã. Isso se deveu a uma compreensão de que elas seriam biologicamente menos racionais que os homens, devendo se ater a atividades vinculadas ao lar e aos cuidados dos filhos. Essas compreensões, como dissemos, são historicamente localizáveis e resultado do entorno social e cultural no qual emergem. Dizemos que elas são contingenciais, isto é, dialogam com as crenças e valores das sociedades e contextos culturais e sociais que as fabricam.

Os Estudos Feministas, de Gênero e de Sexualidades em uma perspectiva de desconstrução têm por propósito, grosso modo, interpelar essas ideias de natureza mostrando seu caráter histórico, isto é, construído e, além disso, evidenciar como que essas construções muitas das vezes são nocivas àquelas pessoas que não se localizam no que as sociedades entendem como normal e natural. Esse foi, e infelizmente ainda o é, o caso das pessoas negras, das mulheres (cis e trans ${ }^{6}$ ) e tem sido, também, das pessoas lésbicas, gays, bissexuais e intersexo. Trocando em miúdos: todas as pessoas que fogem ao padrão normativo: masculino, branco, heterossexual, cristão e europeu.

cultura, isto é, não entendemos ser possível descolar educação e sociedade. A segunda, diz respeito à atenção que as perspectivas queer dão ao campo da cultura. Ao afirmar isso não queremos dizer que tais perspectivas ignorem o caminho legal com vistas a alterar o entendimento das pessoas sobre questões vinculadas ao gênero e à sexualidade, por exemplo. Longe disso, chamamos a atenção, contudo, para a importância da cultura como local no qual se produzem e se perpetuam os preconceitos. Assim, é nela, na cultura, que as perspectivas queer vão concentrar suas investidas políticas, e não no campo das leis.

${ }^{6}$ Cis é prefixo latino, abreviação para cisgênero. A pessoa cisgênero é a que coincide o gênero com o sexo heterodesignado do registro de nascimento. Sendo assim, a mulher cisgênera, por exemplo, é aquela que nasceu e foi registrada mulher e se reivindica mulher, independente de sua orientação sexual. O homem cisgênero é aquele que nasceu e foi registrado homem e se reivindica como tão independente de suas relações afetivo-sexuais. Ao passo que a pessoa trans pode ser aquela que se reivindica com um gênero diferente do que lhe registraram. Trans também é um prefixo do latim e significa 'além de', também é usado como abreviação para travesti e transexual. Neste caso, a mulher trans ou transexual é aquela pessoa que nasceu e foi registrada homem, porém se reconhece mulher, independente do desejo de manter ou não o pênis por meio da cirurgia de resignação de gênero. Sobre a situação dos e das transexuais nos discursos patológicos gerados nas políticas públicas de saúde e assistência no Brasil, ver Revista de Saúde Coletiva, v.19, n.1. 2009.
Não precisamos, dessa forma, tomar como naturais as relações entre os gêneros, as racialidades e as sexualidades em nossas sociedades. Essas relações foram historicamente construídas e podem ser repensadas, problematizadas e desfeitas. Mas por que elas precisam, é o que defendemos, ser desfeitas?, alguém poderia questionar. Ora, elas precisam ser desfeitas porque produzem tratamento desigual entre as pessoas, e o que é pior, profundas violências, que vão desde o simbólico e o psicológico, até violências materiais, que podem desembocar em agressões físicas, estupros ${ }^{7}$ e morte.

O Grupo Gay da Bahia, desde a década de 1990 , tem produzido uma série de chocantes relatórios que tratam de mostrar as violências sofridas pelas populações LGBT (SIMÕES; FACHINNI, 2009). Muito lamentavelmente, os casos de violência material que resultam em morte têm sido mais frequentes do que gostaríamos. Entendemos que essa categoria que nomeia as pessoas diz respeito a diferenças que são socialmente construídas entre homens e mulheres, entre meninos e meninas. Reconhecer a categoria de gênero permite perceber que algumas pessoas são ora privilegiadas ora desfavorecidas em nossas sociedades por conta dessas características. E o que é mais grave: algumas pessoas sofrem violências por conta de serem o que são, como o demonstram os elevados índices sobre estupro, assassinatos de pessoas travestis e transexuais e a violência doméstica. Gênero, portanto, não é uma "ideologia", mas, pelo contrário, um fator sociocultural de produção de desigualdades. E este fator sociocultural tem sido a causa de sofrimentos, mortes e consultórios psiquiátricos lotados.

\section{POR QUE É IMPORTANTE DISCUTIR GÊNERO NAS ESCOLAS?}

As escolas já possuem uma educação sobre gênero e sobre sexualidade (JUNQUEIRA, 2015; JUNQUEIRA, 2009; CAETANO, 2016). Muito embora ela não seja assumida como parte do currículo oficial, mas o "currículo oculto" ${ }^{8}$, essa

\footnotetext{
${ }^{7}$ Pensamos, aqui, tanto nos estupros contra mulheres não trans (cis) quanto nos ditos "estupros corretivos", estes crimes sexuais praticados contra pessoas lésbicas com vistas a "corrigir" sua orientação sexual desviante da heteronorma.

${ }^{8}$ Rita de Cássia Barbosa Paiva Magalhães e Erasmo Miessa Ruiz (2011), em "Estigma e currículo oculto", afirmam que o currículo oculto não se encontra no âmbito do visível, isto é, dos conteúdos e atividades programados, mas sim que se imiscui no cotidiano
} 
educação, que entendemos como uma "pedagogia da sexualidade", diariamente ensina o que é ser menino e o que é ser menina. Como isso se dá? Quando, por exemplo, pensam-se as atividades em "para meninos" e "para meninas"; quando se produz discursos desqualificadores quando meninos brincam de boneca ou se priva as meninas de jogos de bola de futebol, quando as escolas oferecem somente duas atividades extraclasse: futebol para meninos e queimada para meninas! Assim, o que se pretende com este ensaio não é introduzir a temática de gênero e sexualidade nas escolas, uma vez que ela já está lá! Mas sim pensá-la e construí-la democraticamente de maneira a educar para o reconhecimento do direito à diferença, provendo o cuidado da criança e do adolescente e o respeito a todos os modelos de existência, afeto e família.

A escola que dita democrática não pode ser privar do enfrentamento sistemático a toda e qualquer violência e discriminação, a cultura do estupro e os mais diversos tipos de bullying, respeitando a pluralidade humana, característica da própria sociedade em que ela está inserida. $\mathrm{O}$ Brasil viveu uma celeuma em torno dos textos dos planos decenais de educação discutidos no país inteiro. De um lado, discursos fundamentalistas religiosos condenando uma tal de "ideologia de gênero", que constaria nos textos dos planos, e, de outro, grupos de ativistas pelos direitos humanos, sobretudo educadoras, educadores e ativistas feministas e LGBT (lésbicas, gays, bissexuais, travestis e transexuais), defendendo que a educação escolar deva se ocupar de temas como igualdade de gênero, raça e o respeito às diversidades. Celeuma porque as divergências entre os dois grupos repousaram muito mais em um desconhecimento e má-fé dos discursos fundamentalistas religiosos, que em uma discussão séria e teoricamente responsável sobre (1) o que quer dizer gênero, identidade de gênero, sexualidade e diversidade sexual e (2) qual a função da escola na contemporaneidade. No que segue, definimos tais conceitos por meio de uma linguagem mais livre ou ensaística, a

escolar por intermédio da vigilância de comportamentos, das rotinas, dos gestos docentes e, até mesmo aqui acrescentaríamos, por meio da arquitetura da escola, por exemplo, na disposição das carteiras pela sala de aula e na divisão binária (masculino/feminino) das tarefas ministradas. Podemos afirmar, ainda, que a apropriação do espaço escolar pelos e pelas estudantes se dá de maneira a respeitar o binarismo de gênero. mesma que utilizamos em uma formação continuada com docentes da Educação Básica? .

\section{GÊNERO, IDENTIDADE DE GÊNERO, SEXUALIDADE E DIVERSIDADE SEXUAL}

Gênero é um conceito analítico desenvolvido no bojo dos Estudos Feministas, a partir das lutas e politicamente produzido no cotidiano dos movimentos sociais. De acordo com Marta Lamas (2002), o conceito de gênero começa a ser utilizado nas Ciências Sociais como categoria a partir da década de 1970. Desde então, a academia passa a trabalhar com o conceito de gênero, abordando como são construídos culturalmente o ser homem e o ser mulher (CASTRO, 2015).

Nesta abordagem, gênero é a aprendizagem que acontece nas relações socialmente produzidas entre homens e mulheres e destes entre si. Portanto, homens e mulheres aprendem a ser o que são na cultura em que estão inseridos. Seguindo este referencial, as pessoas adultas nos ensinam, desde a infância, como devemos ser homens ou mulheres para sermos socialmente aceitos (SAFFIOTI, 2004), ou seja, a velha e boa conceituação de Simone de Beauvoir (2009) configura-se como eixo: aprendemos a ser mulheres e homens. E como estamos inseridos no contexto histórico patriarcal, aprendemos a ser heterossexuais (homens e mulheres). As mulheres aprendem a ser de alguém e para os outros (LAGARDE, 2011), e o homem aprende, em maior ou menor grau, que deve dominar a mulher, seu corpo e aquilo que dele provém (LAGARDE, 2011; PISANO, 2001; 2004).

Como afirma Louro (1997, p. 21): "para que se compreenda o lugar e as relações de homens e mulheres numa sociedade importa observar não exatamente seus sexos, mas sim tudo o que socialmente se constrói sobre os sexos". Dito dessa forma, pode parecer que o gênero se reduziria, metaforicamente, a uma simples troca cotidiana de roupa, coisa que fazemos constantemente. Mas não é assim. O gênero, mesmo sendo um conjunto muito grande de características, ações, atuações realizadas

\footnotetext{
${ }^{9}$ Nos referimos ao Projeto de Pesquisa "A ideologia em azul e rosa: gênero e sexualidade na educação", desenvolvida no Oeste da Bahia no interior do Programa de Extensão MEC-PROEXT 2016-2017 "Re(ex)sistência LGBT" e as atividades do curso de aperfeiçoamento à Distância "Feminismos, Identidades Político-Sexuais e Educação" no interior do Programa de Extensão MEC-PROEXT 2016-2017 do "Centro de Memória LGBT João Antônio Mascarenhas" no cordão litoral sul do Rio Grande do Sul.
} 
pelas pessoas, não depende exclusivamente delas: depende, antes, de algo mais amplo, da sociedade e das normas de convivência que dizem como cada um de nós precisa ser e se portar para ser respeitado/a, compreendido/a enquanto um ser humano, enquanto uma pessoa. Mais adiante discutiremos isso com maior detalhamento, mas o que importa dizer agora é que, a rigor, não simplesmente inventamos nosso gênero; nossos gêneros estão, dessa forma, de acordo com as normas sociais vigentes na época e no local em que nos encontramos ${ }^{10}$. De maneira sintética: o gênero é social e culturalmente localizável ${ }^{11}$ e por meio dele construímos nossa inteligibilidade social.

Gênero também não é uma "ideologia" como muito se tem falado ultimamente: é, ao contrário, um fato social por meio do qual não apenas identificamos - produzimos uma identidade - uma pessoa, mas, e isso é ruim, produzimos hierarquias, desigualdades ${ }^{12}$. É como nomeamos as violências, ou subalternizações, presentes em nossas sociedades, afirma Louro (1997, p. 55): “é preciso considerar gênero tanto como uma categoria de análise quanto como uma das formas que relações de opressão assumem numa sociedade capitalista, racista e colonialista".

Gênero não é criação de pessoas que querem "destruir a família" ou "ensinar homossexualidade a nossas crianças $^{13}$ ", muito pelo contrário: o gênero é como percebemos, como lemos as pessoas a nossa volta. E algo que vale a pena destacar nesse ponto: gênero diz muito mais respeito a como somos percebidos e percebemos as pessoas e menos como nos identificamos/percebemos a nós mesmos. Não é,

\footnotetext{
${ }^{10}$ A norma de gênero e sexualidade que contemporaneamente orienta a leitura dos corpos humanos e sua consequente separação em dualidades excludentes se chama heteronormatividade.

${ }^{11} \mathrm{O}$ gênero visto de forma dual e excludente, quer dizer, masculino ou feminino, é uma perspectiva ocidental de compreensão das diferenças sexuais. Tal perspectiva, assim como outras ideologias ocidentais, dominou o mundo por meio da colonização - sempre violenta, a qual encontra seu ponto forte na expansão colonial europeia dos séculos XV e XVI. Viviane v (2014) entende que os gêneros e as sexualidades podem ser "descolonizados" e vê no "2espíritos", por exemplo, uma potente possibilidade de resistência às definições coloniais de quem somos. Sobre a expressão de gênero "2-espíritos", recomendamos a leitura do artigo citado de Viviane v.

${ }^{12}$ A violência de gênero, problema social que, lamentavelmente, cresce de maneira assustadora no mundo todo, ensejou a aprovação, no ano passado (2015), da Lei do Feminicídio (13.104/15), a qual modifica o Código Penal brasileiro endurecendo as penas relacionadas a crimes motivados pelo gênero/sexo da vítima.

${ }^{13}$ Essas e outras frases frequentam os discursos de pessoas fundamentalistas religiosas que se opõem à introdução de temas de gênero e sexualidade nos planos municipais de educação brasileiros.
}

portanto, ideologia ou dogma. Mera invenção. Diz respeito a diferenças objetivas que diariamente percebemos entre nossas amizades, familiares, docentes e a nós mesmos/as.

Identidade de gênero, de maneira similar ao conceito de gênero, tem sido utilizado em alguns documentos governamentais e artigos científicos especializados para designar a forma com que a pessoa performatiza (BUTLER, 2014) ${ }^{14}$ o gênero, isto é, para além do que a sociedade aponta como sendo o gênero verdadeiro de uma pessoa, a forma como cada um de nós percebe a si mesmo. Por exemplo: as pessoas travestis e transexuais atribuem a si gêneros que poderíamos chamar transgêneros, que são formas de gênero não necessariamente de acordo com a opinião das demais pessoas que compõem a sociedade. Essas formas de gênero autoatribuídas, sobretudo pelas pessoas travestis e transexuais têm sido nomeadas, portanto, de "identidade de gênero".

Anteriormente destacamos que 0 conceito de gênero diz muito mais respeito a como somos percebidos e como percebemos as demais pessoas e menos como nos percebemos a nós mesmos. Ocorre que tal afirmação foi feita de maneira parcial e para ajudar a compreensão mais básica que se tem de gênero, um entendimento mais vinculado a uma primeira reflexão teórica sobre gênero, formulada, sobretudo pelos primeiros grupos e núcleos sobre o tema tanto no Brasil quanto ao redor do mundo. Contudo, estudos mais recentes no campo dos Estudos de Gênero e das Sexualidades (COLLING, 2015), feitos de maneira interdisciplinar, quer dizer, desde várias disciplinas acadêmicas, têm afirmado que independentemente de sermos pessoas travestis e transexuais, todos e todas nós produzimos nossos gêneros ao não só percebermos e lermos as pessoas que nos rodeiam, e assim atribuir-lhes um gênero, como também nos percebemos e nos lermos a nós mesmos, produzindo inúmeras possibilidades de se fazer masculino ou feminino.

\footnotetext{
14 Apresentado por Judith Butler em Problemas de Gênero, o conceito de performatividade de gênero diz respeito aos rituais culturais que produzem o gênero por meio da repetição, ou seja, da citacionalidade. Da mesma forma que a drag expõe toda a artificialidade da feminilidade, o próprio gênero é ficcional, quer dizer, produzido, porquanto efeito de discursos proferidos no interior da cultura. Diferentemente do conceito de performance, que supõe um sujeito por detrás da máscara a conduzir o espetáculo, na performatividade não há, segundo Butler, sujeito anterior ao discurso, mas sim é o próprio discurso que produz, performativamente, os sujeitos. Sobre o conceito de performatividade, ver Pablo Pérez Navarro (2008).
} 
Vale citar aqui o documento produzido pelas Nações Unidas denominado "Princípios de Yogyakarta", o qual traz o conceito de identidade de gênero, base das reflexões aqui apresentadas:

ENTENDO "identidade de gênero" como estando referida à experiência interna, individual e profundamente sentida que cada pessoa tem em relação ao gênero, que pode, ou não, corresponder ao sexo atribuído no nascimento, incluindo-se aí o sentimento pessoal do corpo (que pode envolver, por livre escolha, modificação da aparência ou função corporal por meios médicos, cirúrgicos ou outros) e outras expressões de gênero, inclusive o modo de vestirse, o modo de falar e maneirismos (PRINCÍPIOS DE YOGYAKARTA apud TORRES, 2013).

Falou-se anteriormente também que a questão das normas seria abordada, das regras que orientam, que regulam nossos gêneros. Mesmo que, como vimos, nossos gêneros sejam produzidos por nós e pelas pessoas que nos rodeiam, eles não são produzidos a partir do nada: são as sociedades e suas normas, efetivamente a moral que emprega, que diz o que é um gênero possível e aceitável. É o que pesquisadoras, pesquisadores e ativistas têm chamado "matriz de inteligibilidade sexual" (BUTLER, 2014). É por isso que alguns tipos de masculinidade, como os homens que são extremamente educados para determinado grupo social e/ou localidade ou outros que não jogam futebol, por exemplo, têm sua masculinidade heterossexual posta em dúvida. Eles têm seu gênero colocado sob suspeita. É um tipo de masculinidade, essa a dos exemplos, que não é aprovada no exame de gênero criado pela sociedade. Mulheres que "trabalham fora", sem filhos; mulheres líderes, chefes em seus trabalhos, todas elas também, em alguma medida, se distanciam e, por isso, são reprovadas no teste de gênero imposto pela sociedade heteronormativa. É uma feminilidade que vacila na visão da sociedade que regula e sanciona aquelas pessoas que se afastam de seus ditames. Esse tipo de entendimento sobre as relações de gênero e as sexualidades é baseado na norma sexual e de gênero vigente no Ocidente, que chamamos "heteronormatividade" (MISKOLCI, 2012).

A heteronormatividade parte do princípio de que todas as pessoas devem atuar e ser referenciada a partir e com a heterossexualidade, mesmo não a sendo. E mais: a lógica existencial a reger a vida de todos e todas afirma que eles devem ser ou socialmente comportar-se como pessoas hétero. É por isso que se diz nos Estudos sobre Gênero e Sexualidades que a cultura ocidental e, por conseguinte, a escola como parte de sua estrutura, fazem propagandas objetivas de legitimidade exclusiva da identidade sexual heterossexual. Não havendo, nesse processo, "opção" alguma, mas uma oferta única de socialmente viver e se comportar sexualmente. Assim, pode-se dizer que a escola comporta-se, por meio de seus currículos, hegemonicamente heterossexista, além de sexista, posto que não só parte do pressuposto de que todos e todas são heterossexuais, como ainda privilegia o ser homem por sobre o ser mulher, o masculino por sobre o feminino.

Mas além de regular, de normatizar, as sociedades, as escolas, como parte da maquinaria que educa os sujeitos, terminam por normalizar aquelas expressões de gênero e sexualidades que consideram legítimas, verdadeiras, aceitáveis. Ao tornar algumas expressões de gênero normais, as regras sociais produzem profundas violências naqueles sujeitos que ousam delas se desviar. É o caso das pessoas travestis e transexuais, por exemplo, mas não só: também daquelas pessoas dos exemplos que anteriormente mencionamos. É por isso que, como veremos adiante, a escola precisa investir em uma educação que destitua todo o tipo de violência, dando especial atenção às violências de gênero, ou seja, àquelas que são efeito direto da leitura de um gênero que se desvia das normas socialmente estabelecidas para cada sexo.

Essas violências são resultado da forma como nossa sociedade lê, como ela enxerga, como ela compreende as mulheres: enquanto pessoas subservientes, naturalmente submissas e disponíveis à força do homem. É preciso alterar esse entendimento, que, assim nos parece, todos e todas nós concordemos que é equivocado e produtor de violências. As lutas por mudança nos entendimentos, assevera Louro (2008, p. 20), são 
travadas no interior da cultura. Diz Stuart Hall é agora um dos elementos mais dinâmicos e mais imprevisíveis da mudança histórica do novo milênio. Daí porque não deve nos surpreender que as lutas pelo poder sejam, crescentemente, simbólicas e discursivas, ao invés de tomar, simplesmente uma forma física e compulsiva, e que as próprias políticas assumam progressivamente a feição de uma "política cultural" (HALL, 1997, p. 20).

Rogério Diniz Junqueira (2014) aponta que ambientes que menosprezam, que injuriam certas pessoas, produzem subjetividades marcadas por poderosos processos de assujeitamento, de subserviência e naturalização de discursos injuriosos. As pessoas negras, conforme ele aponta, são submetidas a uma escolarização extremamente racista e produtora de violências. Os e as estudantes negros e negras, expostos/as diariamente a injúrias raciais, para além de violência simbólica ao não serem contemplados nos conteúdos escolares, frequentemente sentem-se menores, incapazes e menos inteligentes que os $\mathrm{e}$ as estudantes brancos. Da mesma forma, os e as estudantes cujos gêneros, sexualidades e corporalidades estão em desacordo às normas dominantes estão sujeitos a violentos mecanismos de assujeitamentos.

De modo geral, a negritude aparece no currículo escolar ora como algo episódico, a exemplo do "Dia da Consciência Negra" ou a "Abolição da Escravatura", ora como vinculada a estereótipos profundamente negativos. Ou seja, muito embora as Leis Federais 10.639/2003 e $11.645 / 2006$ tenham mais de uma década, não conseguimos, como sociedade, trabalhar raça/etnia de modo a tornar essa questão um problema de todas as pessoas. A discussão sobre sexualidade no ambiente escolar também passa por problema similar. Quando aparece, é apenas para introduzir temas relacionados à gravidez na adolescência e ou à prevenção de doenças, como o HIV/Aids. O que é importante, evidentemente, mas que não deve, de maneira alguma, circunscrever o aparecimento da temática no currículo. É preciso, assim entendermos, associar a sexualidade ao prazer como direito humano e não como algo circunscrito ao campo da saúde/doença e, consequentemente, do perigo e da morte ${ }^{15}$.

\footnotetext{
${ }^{15}$ Parece-nos de grande relevância chamar a atenção aqui para o tratamento que as campanhas, sobretudo as governamentais, dão às pessoas que vivem com HIV/Aids: em vez de destacar que uma
}

Quanto à sexualidade e à diversidade sexual, tais conceitos serão abordados de maneira conjunta, entendidos como o desdobramento um do outro quando a questão em pauta é a promoção de uma educação que defenda a criança e que contribua para um mundo no qual ser mulher ou homem não defina o destino de nenhuma pessoa. Em relação à sexualidade, vale dizer que ela diz respeito muito mais além que o sexo, entendido como o ato sexual e as genitálias. Sexualidade é uma categoria ampla e envolve desde os nossos desejos presentes até possibilidades outras de prazer e fantasias futuras, além da dimensão afetiva e as formas como nos percebemos e como somos percebidos pelos demais. Coisas que (ainda) não sabemos de nós, que estamos por inventar. Devires, possibilidades... Sexualidade, dessa maneira, não deve ser reduzida ao ato sexual e às genitálias. Conforme Richard Miskolci (2012, p. 39):

[...] A sexualidade envolve desejo, afeto, autocompreensão e até a imagem que os outros têm de nós. A sexualidade tende a ser vista, por cada um de nós, como nossa própria intimidade, a parte mais reservada, às vezes até secreta, de nosso eu. Assim, não surpreende que a sociedade tenha encontrado nela um meio de normalizar as pessoas.

A diversidade sexual (TORRES, 2013) é um conceito extremamente importante para a educação. Uma educação que não educa para a diversidade, seja ela qual for, perde o sentido republicano de educar para o convívio em sociedade, isso porque a educação não é neutra (FREIRE, 2001). A escola enquanto agente e lugar privilegiado de promoção de transformações sociais tem entre suas funções oferecer uma formação que eduque para a vida, para toda a pluralidade e diversidade que a vida oferece ao mundo. A Educação é, acima de tudo, um político (FREIRE, 2001; 2003).

\footnotetext{
vida com o vírus é possível, tais campanhas, verdadeiras peças educativas, terminam, em sua maioria, por invisibilizar as pessoas soropositivas ao centrarem seus esforços tão somente no combate à infecção. O que queremos dizer com essa afirmação é que, dessa forma, os preconceitos contra as pessoas que vivem com HIV/Aids não serão desfeitos tão cedo.
} 
A vida é assim, mesmo que discursos das mais distintas naturezas não o queiram: múltipla, diversa e diferente a cada dia. Educar para a diversidade sexual, nesse sentido, diz respeito a não privilegiar uma forma de vida como modelo para todas as pessoas. Significa, portanto, antepor-se a uma educação heterossexista. Significa, ainda, não privilegiar uma expressão de gênero e de sexualidade em prejuízo de tantas outras.

A escola, desde sua fundação, tem ensinado dentro de um paradigma heterossexual e nem por isso todas e todos são heterossexuais, coisa que nos alerta para abandonarmos a absurda ideia de que uma educação que considere a diversidade sexual ensinaria as e os estudantes a serem homossexuais ou transexuais. Lamentavelmente, a escola tem contribuído, hegemonicamente, não para o acesso, a permanência e o sucesso de estudantes que se afastam das normas de gênero $e$ sexualidade e sim para a sua expulsão:

[...] não existe indicadores para medir a homofobia de uma sociedade e, quando se fala em escola, tudo aparece sob o manto invisibilizante da evasão. Na verdade, há um desejo de eliminar e excluir aqueles que contaminam o espaço escolar. Há um processo de expulsão, e não de evasão. É importante diferenciar evasão de expulsão, pois, ao apontar com maior precisão as causas que levam crianças a não frequentarem 0 espaço escolar, se terá como enfrentar com eficácia os dilemas que constituem o cotidiano escolar, entre eles, a intolerância alimentada pela homofobia (BENTO, 2011, p. 555).

Numerosas são as pesquisas científicas que indicam que estudantes travestis e transexuais têm sérios problemas em se manter nas escolas (ANDRADE, 2012). Não diferentes são estudantes gays e lésbicas que não performatizam 0 gênero no interior das expectativas definidas ao universo masculino ou feminino.

\section{A ESCOLA E AS IDENTIDADES SEXO-GÊNERO DISSIDENTES ${ }^{16}$}

Muitos são os casos de meninos que são diariamente classificados como afeminados e de meninas classificadas masculinizadas que sofrem desde a ridicularização diária, em uma tortura que causa sérios danos psicológicos, até espancamentos, e no cúmulo dessa crucificação, são vítimas de mortes medonhas e cruéis. $O$ que violenta, às vezes matando, esses meninos afeminados e meninas masculinizadas nada mais é que o gênero lido como anormal, como contrário às regras e normas vigentes na sociedade. Assim, entender o gênero como uma ideologia, parece ser um desejo explícito de ignorar a realidade cinza de nossas escolas, de nossas famílias, de nossas ruas, de nosso país. Giancarlo Cornejo (apud MISKOLCl, 2012) chega a dizer que há uma "guerra declarada contra o menino afeminado" e nos acrescentaríamos as meninas masculinizadas. E, nessa luta cruenta, defendemos uma escola que precisa tomar a posição não de algoz, mas sim de aliada das crianças e adolescentes cujas performatividades de gênero se distanciem dos ditames da heteronorma.

Entendemos que a escola tem lado, mas não o lado e o ideário daqueles e daquelas que governam segundo compreensões muito estritas da vida, e sim o lado do respeito às diferenças, o lado da defesa da pluralidade. Com a intensificação do sentimento democrático, o Ocidente viu crescer em seu interior resistências a um modelo de escola e de educação normativo e (re)produtor de violências. A incompletude da existência nos faz refletir o conceito de cidadania porque esta consiste em um ato no qual os sujeitos deixam suas contribuições às necessidades sociais, ao pensamento crítico e às eleições da vida. Esta última, não diferentes das duas primeiras, implica, em primeiro lugar, a radicalidade democrática.

Pode parecer estranho aplicar o conceito democracia ao âmbito das dimensões sexuais, porém, sem dúvida, se necessita um novo conceito de democracia quando falamos do direito a controlar nossos corpos. Quando

\footnotetext{
${ }^{16}$ Com vistas a não empacotar as pessoas nas letras "LGBT" é que nos utilizamos da expressão "sexo-gênero dissidentes". São pessoas que, em alguma medida, se distanciam do que a heteronormatividade institui como o normal, o aceitável.
} 
dissemos: nossos corpos são de nossa propriedade! Com eles estamos fazendo política. Mesmo que o mundo possa existir com nossa ausência, nossa presença no mundo exige criatividade. Neste sentido, viver criativamente é condição para expandir a democracia e se criar com a democracia.

Ao trazer esses elementos pensamos, sobretudo, nos movimentos sindicais; nos movimentos pelos direitos civis de mulheres, indígenas, negros e negras, LGBT; nas revoluções e "liberações" sexuais; na descolonização da África. Todos esses movimentos, somados, forçaram/forçam os Estados nacionais a se não desfazer pelo menos visibilizar os ideários, ou seja, as ideologias que dominavam hegemonicamente os fazeres da escola. Tudo isso que afirmamos é para evidenciar que, depois desses movimentos todos, desejar uma escola e uma educação neutra, não política, como preconiza o "Movimento Escola Sem Partido", não é possível. Ivone Gebara (1997, p. 32) pontua: "Não há neutralidade possível mesmo que não estejamos conscientes da situação em que vivemos e não conheçamos o sistema de influências que nos atinge".

A educação, como a posicionamos e, por conseguinte, a escola, devem, sim, ter política, ou seja, ter lado. Como assim? É preciso dizer que houve um tempo em que a escola serviu aos interesses das elites econômicas e culturais dos Estados nacionais, operando no sentido de formar para certa cidadania. $\mathrm{Na}$ contemporaneidade, a escola precisa se preocupar com, em primeiro lugar, demonstrar que o ato de educar é um ato humano e, como tal, desde já comprometido. Uma educação e uma escola que não partem do contraditório, do plural, educam para, como antes mencionamos, o pensamento único, que, por si só, produz violências, posto que, ao se afirmar como verdadeiro, nega todas as demais possibilidades de ver e estar no mundo.

Quando se propõe discutir as relações de gênero, as sexualidades e as dimensões étnicoraciais e de classe nas escolas o que se pretende é ir para muito além de uma abordagem biológica e simplistas das desigualdades entre os seres humanos. O que se pretende é ensinar estudantes a questionarem as hierarquias sociais e a respeitarem seus corpos, e, com isso, respeitarem os corpos das demais pessoas, o que acarretaria em uma profunda tomada de consciência por parte da criança e/ou adolescente em relação a si. Tal tomada de consciência, acreditamos, tornaria casos de abuso sexual infantil, por exemplo, muito difíceis. Contribuiria para reduzir os casos de violência sexual. Crianças e adolescentes conscientes de seus corpos não só os protege, como ainda também impede que outros corpos sejam violentados. É uma educação para a sexualidade. Uma educação para o respeito à criança e ao adolescente. Uma educação que ensina a cuidar de si e a cuidar do outro.

As pessoas sexo-gênero dissidentes, cotidianamente e em especial na escola, estão expostas a três formas de violências: (1) simbólicas, (2) psicológicas e (3) materiais. Quanto à primeira forma de violência, é preciso que entendamos o papel da cultura, tomada em acepção ampla que compreende o campo das representações, como instância que produz e reproduz compreensões, muitas das vezes equivocadas, sobre as minorias. Por exemplo, quando uma telenovela reiteradamente coloca pessoas negras para representarem papéis de empregadas domésticas, ladrões, malandros, usuários de drogas ilícitas termina por cristalizar certa representação sobre as identidades negras. Trata-se de uma reiteração que naturaliza certas identidades. A reiteração ou citação é movimento indispensável para o processamento das naturalizações culturais. $O$ mesmo ocorre com as pessoas não heterossexuais, as quais, à exceção de algumas poucas novelas da última década, têm sido associadas ao risível e a uma vida na qual não há sexo.

Tais representações, defendemos, promovem violências simbólicas, porquanto soldam as identidades negras, não heterossexuais e gênero-dissidentes a estereótipos extremamente nocivos. A discussão em torno à representatividade também ganha sentido nesse ponto, já que, para as pessoas cujas identidades se fundam na injúria (negras, não heterossexuais, com deficiência física etc.), ver-se representadas de maneira positiva em uma publicidade, na cor de uma boneca infantil, no professor gay da universidade etc., é central para a (re)construção de suas subjetividades já extremamente fraturadas. A violência simbólica é, portanto, do âmbito das representações.

Já as violências psicológicas, dizem respeito a como a LGBTfobia $^{17}$ e outras

\footnotetext{
${ }^{17}$ Dada à disputa interna nos movimentos sociais que denunciam de que o conceito "homofobia" apenas visibiliza as vivências violentas de homens gay, optamos por usar o termo LGBTfobia. Entretanto,
} 
modalidades de subalternização podem provocar graves sequelas, do ponto de vista da subjetividade, nos sujeitos injuriados. Seguindo Judith Butler (2014), seria possível afirmar que a injúria é o elemento comum responsável por fundar as subjetividades minoritárias. Aqui a violência se localiza no âmbito do indivíduo, a partir de insultos e injúrias cujo propósito é desfazer o eu, desencadeando um movimento de minoração do sujeito, de subjetivação minoritária. De maneira rápida, as violências psicológicas querem despossuir o sujeito da humanidade. Talvez valesse associar esse movimento de subjetivação minoritária a um atavismo colonial cujo interesse é o (re)estabelecimento do que Boaventura de Sousa Santos (2009), nomeia "linha abissal", a qual tem por propósito definir quem é digno e quem não é digno do estatuto da humanidade. Por fim, as violências materiais são, de modo geral, a ponta de um largo e tortuoso caminho de violências. Elas se referem às agressões físicas e, lamentavelmente mais frequentes, a assassinatos de LGBT's.

Se a escola tem entre suas funções a de formar para a diversidade, para a pluralidade que é a vida humana na Terra, nada mais justo e correto que incluir em seus currículos discussões sobre sexualidade, gênero, relações etnicorraciais e outras diversidades, como o são os exemplos das diversidades religiosas. Não há argumentos, após o que apresentamos, que consigam sustentar a exclusão desses temas de nossas escolas. Mau-caratismo e dogmas religiosos, inimigos das crianças e das famílias plurais e diversas, não conseguem se manter de pé se o campo de embate for o que se tratou de aqui delinear: o do combate às violências de gênero, da promoção da igualdade, do reconhecimento da diferença e da defesa e proteção da criança e do adolescente.

\section{CONSIDERAÇÕES FINAIS}

As expectativas criadas em torno das performatividades de gênero e a nomeação de doença orientaram as imagens e as linguagens associadas às LGBT's. Na contemporaneidade, dada a radicalidade com que emergem as forças conservadoras orientadas pelo saber judaico-

pensamos que os conceitos "Homofobia" e "LGBTfobia" não expressam a complexidade que envolve a estrutura heteronormativa, sobretudo, quando a cruzamos com as discussões em torno das performatividades de gênero, misoginia e androcentrismo. cristão e pela intransigência da família patriarcal, a violência contra LGBT ainda faz parte do cotidiano e é amplamente divulgada na imprensa nas cidades de pequeno e médio porte. Entendemos que a violência contra LGBT's, assim como aquelas vividas pelas populações negras e mais amplamente mulheres, ao longo da história da sociedade brasileira sempre esteve associada à visibilidade e a forma com que é ocupado o espaço público. Para os setores conservadores visualizar as camadas subalternizadas articulando-se e reivindicando espaço de igual valor entre os interesses que circulam a polis, opera-se como afronta à tradição.

O desejo e o sonho são elementos abstratos que unidos são capazes de materializar as transformações da vida. O desejo vem movendo homens e mulheres a visibilizarem suas especificidades em um mundo público no qual a diferença é capaz de gerar hierarquias. No entanto, somente demarcando os espaços da diferença é possível visibilizar as especificidades e materializar no real aquilo que ainda se encontra nos sonhos. Os sonhos moveram e movem LGBT's, a ousadia de dizer o nome de quem se ama e fez com que as Paradas do Orgulho LGBT sejam hoje o ato de maior mobilização política de massa do Brasil. Assim sendo, o conceito de inclusão social somente será eficaz e terá sentido se levar em consideração os direitos do ser humano em práticas universalistas e agregadoras. Portanto, todo ser humano, independentemente de sua posição no mundo, tem o direito à auto aceitação, às relações sociais positivas, orientadas pelo respeito, qualificação e acolhimento, à autonomia, à determinação de sua própria vida e realizações, à autoestima, à razão de viver e ao crescimento pessoal e social. E são esses valores que defendemos, sonhamos e por eles nos mantemos como educador (es/as).

\section{REFERÊNCIAS}

ANDRADE, Luma Nogueira de. Travestis na escola: assujeitamento à ordem normativa. 2012. 278f. Tese (doutorado) - Universidade Federal do Ceará, Faculdade de Educação, Programa de PósGraduação em Educação, Fortaleza, 2012.

BEAUVOIR, Simone. O segundo sexo. Rio de Janeiro: Nova Fronteira, 2009.

BENTO, Berenice. Na escola se aprende que a diferença faz a diferença. Revista Estudos 
Feministas, Florianópolis, v. 19, n.2, p. 549-559, 2011. Disponível

em: https://doi.org/10.1590/S0104-

026X2011000200016 Acesso em: 22 nov. 2016.

BUTLER, Judith. Problemas de gênero. Rio de Janeiro: Civilização Brasileira, 2014.

CAETANO, Marcio. Performatividades reguladas: heteronormatividade, narrativas biográficas e educação. Curitiba: Appris, 2016.

CASTRO, Amanda Motta. Fios, tramas, cores, repassos e inventabilidade: $A$ formação de tecelãs em Resende Costa, MG. 2015. 230f. Tese (Doutorado em Educação) - Programa de PósGraduação em Educação, Centro de Ciências Humanas. São Leopoldo: Universidade do Vale do Rio dos Sinos, 2015.

COLLING, Leandro. Que os outros sejam o normal. Tensões entre o movimento LGBT e o ativismo queer. Salvador: Edufba, 2015.

FOUCAULT, Michel. Nietzche, a genealogia e a história. In: FOUCAULT, Michel. Microfísica do poder. Rio de Janeiro: Edições Graal, 1979. p. 1538.

FREIRE, Paulo. Pedagogia da autonomia: saberes necessários à prática educativa. 25. ed. São Paulo: Paz e Terra, 2001.

FREIRE, Paulo. Pedagogia do oprimido. 45. ed. São Paulo: Paz e Terra, 2003.

GEBARA, Ivone. Teologia ecofeminista. São Paulo: Olho D’Água, 1997.

JUNQUEIRA, Rogério Diniz. Introdução. Homofobia nas escolas: um problema de todos. In: JUNQUEIRA, Rogério Diniz. Diversidade sexual na educação: problematizações sobre a homofobia nas escolas. Brasília: Ministério da Educação, Secretaria de Educação Continuada, Alfabetização e Diversidade, UNESCO, 2009. p. 367-444.

JUNQUEIRA, Rogério Diniz. "Temos um problema em nossa escola: um garoto afeminado demais": Pedagogia do armário e currículo em ação. Revista Educação e Políticas em Debate, v. 4, n. 2, p. 221-239, ago./dez. 2015.
LAGARDE, Marcela. Cautiverios de las mujeres: madresposas, monjas, putas, presas y locas. 4. ed. Ciudaddel México: UNAM, 2011.

LAMAS, Marta. Cuerpo: diferencia sexual y género. Ciudade del Mexico: Taurus, 2002.

LOURO, Guacira Lopes. Gênero, sexualidade e educação: uma perspectiva pós-estruturalista: Petrópolis: Vozes, 1997.

LOURO, Guacira Lopes. Teoria Queer - uma política pós-identitária para a educação. Estudos Feministas, Florianópolis, v. 9, n. 2, p. 541, jan. $2001 . \quad$ Disponível em: https://doi.org/10.1590/S0104026X2001000200012. Acesso em: 22 nov. 2016.

LOURO, Guacira Lopes. Gênero e sexualidades: pedagogias contemporâneas. Pro-Posições, Campinas, v. 19 , n. 2 (56), p. 17-23, mai./ago. $2008 . \quad$ Disponível em: https://doi.org/10.1590/S010373072008000200003 Acesso em: 22 nov. 2016.

MISKOLCI, Richard. Teoria queer: um aprendizado pelas diferenças. Belo Horizonte: Autêntica, 2012.

NAVARRO, Pablo Pérez. Del texto al sexo. Judith Butler y la performatividad. Barcelona/Madrid: Editorial Egales, 2008.

SAFFIOTI, Heleith. O poder do macho. São Paulo, Moderna, 2004.

SANTOS, Boaventura de Sousa. Epistemologias do Sul. Coimbra: Edições Medina, 2009.

SIMÕES, Júlio; FACCHINI, Regina. Na trilha do arco-íris. Do movimento homossexual ao LGBT. São Paulo: Fundação Perseu Abramo, 2009.

TORRES, Marco Antonio. A diversidade sexual na educação e os direitos de cidadania LGBT na escola. Belo Horizonte: Autêntica Editora; Ouro Preto: UFOP, 2013.

V, Viviane. Trans* Sexualidade: Reflexões sobre a mercantilização do sexo desde uma perspectiva transgênera. Revista Periódicus, Salvador, v. 1, n. 1, p. 1-17, mai./out. 2014. Disponível em: https://portalseer.ufba.br/index.php/revistaperio 
dicus/article/view/10154. Acesso em 26 nov.

2016. https://doi.org/10.9771/peri.v1i1.10154 